\title{
Fine-scale habitat use and behavior of a nearshore fish community: nursery functions, predation avoidance, and spatiotemporal habitat partitioning
}

\author{
S. H. Munsch*, J. R. Cordell, J. D. Toft \\ School of Aquatic and Fishery Sciences, University of Washington, 1122 NE Boat St., Seattle, WA 98115, USA
}

ABSTRACT: We have a limited understanding of habitat use and behavior in nearshore fish communities because they are rarely observed in situ. Consequently, ecologists recommend a process-based conceptualization of nursery habitats, but lack knowledge of nursery processes on fine scales along shore, and studies in controlled settings suggest that context-dependent behaviors allow fish to balance predation avoidance with other objectives, but there is little observational corroboration of these behaviors in situ. We used a long-term dataset of underwater observations to quantify the fine-scale habitat use and behavior of a shallow estuarine fish community. We asked, 'Within species, how does behavior vary with habitat context and developmental stage?' and 'Do species partition habitats in space and time?' We found that smaller fish occupied shallower depths where predators were less abundant; smaller fish schooled in larger groups; pelagic fish schooled in larger groups in deeper water; demersal fish schooled in larger groups when occupying the water column; and species partitioned habitats by depth and season. Additionally, smaller fish were proportionally less abundant along deep shorelines created by intertidal armoring. Overall, habitat use was suggestive of nursery functions, including ontogenetic habitat shifts, provision of predator refuge, and appropriate food/predation risk tradeoffs. Additionally, fish behaved in a manner consistent with adaptive decisionmaking to avoid predation, and time and space may be important axes on which transient juveniles partition habitats. Some nursery functions appeared to be mediated by a shallow depth gradient, which may be compromised by shoreline infrastructure and rising sea levels along built shorelines.

KEY WORDS: Nursery · Habitat selection · Schooling · Ontogenetic behavior shift · Coastal squeeze . Predation risk $\cdot$ Shoreline development $\cdot$ Estuary

*Corresponding author: smunsch@uw.edu
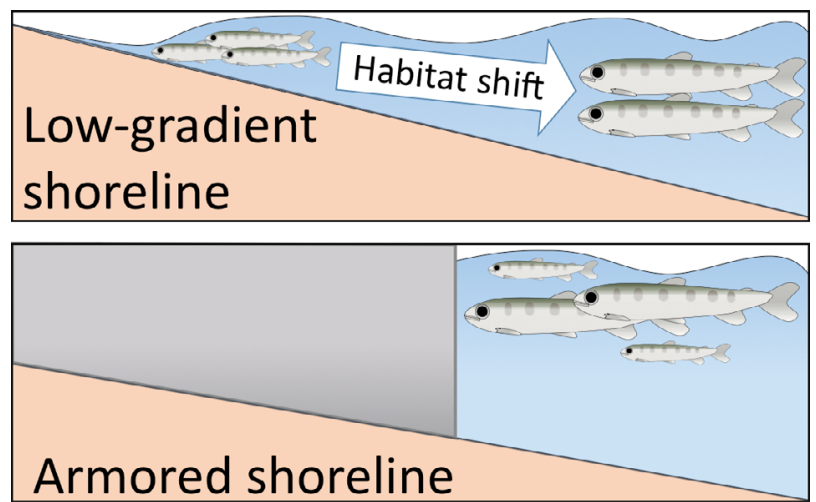

Nearshore waters support potentially adaptive ontogenetic habitat shifts, which are disrupted by shoreline armoring that eliminate shallows.

Diagram: S. H. Munsch

\section{INTRODUCTION}

Ecology and conservation are founded on natural history. To guide management and research, we must understand 'how and where [organisms] live, and the biotic and abiotic interactions that link them to communities and ecosystems' (Tewksbury et al. 2014 , p. 300). In fish, this understanding is often incomplete because their behavior is difficult to observe in situ (Able 2016). Two consequences of this knowledge gap are that (1) we recognize that nearshore waters provide nursery functions for fish (Beck et al. 2001), but have an incomplete understanding of the fine-scale processes and habitat features that promote juvenile fitness (Sheaves et al. 2015), and (2) studies in controlled settings suggest that contextdependent behaviors are essential for fish to balance

(C) The authors 2016. Open Access under Creative Commons by Attribution Licence. Use, distribution and reproduction are unrestricted. Authors and original publication must be credited. 
predation avoidance with other life history objectives (e.g. Hoare et al. 2004), but there are few in situ observations to corroborate these behaviors occurring in nature. Behavioral linkages between fish and their shallow habitats are important to understand because shallow areas have been modified globally by anthropogenic activities (Doody 2004, Bulleri \& Chapman 2010, Temmerman et al. 2013) and their ecological functions cascade to connected systems (Sheaves et al. 2015). Thus, we can inform the conservation of aquatic ecosystems and basic fish ecology by understanding the natural history of nearshore communities.

Nearshore ecosystems provide nursery functions to fish. Ecologists have long recognized that shallow waters are often densely inhabited by juvenile fish, highly productive, and low in predator densities (Beck et al. 2001). Building on these observations, nursery habitats were conceptualized as areas that contributed substantial numbers of juveniles to adult populations and were evaluated by their output of juvenile biomass (Beck et al. 2001, Dahlgren et al. 2006). However, this model was criticized because it did not account for dynamics of habitat use and the functions that support them (Sheaves et al. 2006). A recent, more sophisticated nursery concept has shifted to a process-based perspective and included habitat functions such as predictable ontogenetic habitat shifts, appropriate food/predation tradeoffs, and connectivity (Nagelkerken et al. 2015, Sheaves et al. 2015). That is, nurseries facilitate the survival of juveniles by providing access to resources or environments at appropriate stages. Following this framework, we can better understand how fish benefit from nearshore ecosystems by studying their fine-scale habitat use and behavior.

Nearshore fish communities are typically studied using physical capture (e.g. netting) rather than observing behavior directly. As a consequence, it is difficult to connect their fine-scale habitat use and behavior to basic ecological theory. First, the behavior of fish in nearshore waters may be driven by tradeoffs between predation risk and other life history objectives (Lima \& Dill 1990). Microhabitat selection and schooling can reduce predation risk, but at potential costs. Shallower habitats are thought to offer relatively safe environments because larger aquatic predators are uncommon or ineffective in confined spaces (Paterson \& Whitfield 2000), but these areas also limit the search space of foragers, and their prey fields (e.g. small invertebrates) may become less preferable as juveniles grow (e.g. Duffy et al. 2010). Likewise, structured areas offer camou- flage and cover, but fish restricted to these areas may experience limited foraging (Werner et al. 1983). In a similar tradeoff, schooling reduces predation risk by diluting the probability of capture, increasing vigilance, and confusing predators (Pitcher \& Parrish 1993), but increases competition for resources with conspecifics (Alexander 1974, Grand \& Dill 1999, Hoare et al. 2004). Size is an additional determinate of predation risk that may mediate habitat selection and schooling because larger fish have fewer gapelimited predators and greater escape capabilities (Sogard 1997). Collectively, these factors may influence context-dependent behavior in nearshore communities because fish employ behaviors that minimize predation, while scaling these behaviors to balance safety with the benefits of other objectives (Dill 1983, Lima \& Dill 1990, Hoare et al. 2004).

Next, nearshore fish communities may partition habitats in time and space. Compared to space, time is a less studied yet important axis on which consumers partition habitats (Kronfeld-Schor \& Dayan 2003). In nearshore waters, juveniles are often transient (Nagelkerken et al. 2015) and species occupy variable depth distributions (e.g. Munsch et al. 2015b). Fish may thus reduce competition by minimizing overlap in time and space, but to understand this requires fine-scale knowledge of when and where they occur.

Here we used a long-term dataset of in situ observations to quantify the fine-scale habitat use and behavior of a shallow estuarine fish community. Our first, broader question was, 'Within species, how does fish behavior vary with habitat context and the developmental stage of fish?' We addressed this question through a series of comparisons. First, we compared the size of fish to the depth at which they occurred. We hypothesized that smaller fish would occupy shallower depths because smaller fish are more vulnerable to predation (Sogard 1997) and shallow areas provide protection from predators (McIvor \& Odum 1988, Paterson \& Whitfield 2000). Given the anticipated relationship between fish depth and length, we also compared the size distribution of fish along shorelines with shallow habitat to shorelines where intertidal armoring (e.g. seawalls, riprap) eliminated shallow waters directly adjacent to shore. We hypothesized that small fish would be proportionally more abundant along shores with lowgradient, shallow habitat. Second, we compared the size of fish groups to the length of fish in these groups. We hypothesized that smaller, more vulnerable fish would occur in larger groups because (1) schooling reduces risk of predation (Pitcher \& Parrish 
1993) and (2) for some species, smaller individuals are most abundant and fish school with conspecifics of similar size (Hoare et al. 2000). Third, we compared the group size of fish using the water column, to water depth. We hypothesized that these fish would occur in larger groups when they were in deeper waters because (1) deeper waters do not provide spatial refuge from larger predators and deeper waters provide predators vantage points to detect backlit fish in the water column; and (2) school size is spatially limited in shallow areas. Finally, we compared the school size of demersal fish to the portion of the water column they occupied. We hypothesized that these fish would occur in larger groups when they were away from camouflaging substrate and algae on the bottom and presumably more conspicuous to predators. Our second, more specific question was, 'How do species partition habitats in space and time?' We described spatiotemporal habitat partitioning by examining how the composition of the fish assemblage varied by depth and month.

\section{MATERIALS AND METHODS}

\section{Study system}

Fish were observed in nearshore waters of Puget Sound, Washington, USA; a $31440 \mathrm{~km}^{2}$ fjordal estuary with cold-temperate waters. The bottom structure of shallow areas is comprised of mixed sediments, including sand, gravel, and large rocks. In addition, seawalls and riprap (angular boulders) are commonly used as shoreline armoring in Puget Sound, especially around urban centers. Brown, green, and red macroalgae are common on bottom substrates. The middle and top of the water column lacks structure, with the exception of beds of bull kelp Nereocystis luetkeana buoyed by pneumatocysts. Pilings that support piers are also common along shore and add structure to the water column; however, we excluded observations of fish under piers in this analysis because pier shading can influence fish behavior (e.g. Able et al. 2013, Munsch et al. 2014).

Abundant fish in the nearshore waters of Puget Sound include surfperches (family Embiotocidae), juvenile Pacific salmon (Oncorhynchus spp.), and forage fish (e.g. Pacific herring Clupea pallasii, surf smelt Hypomesus pretiosus), which we refer to in functional groupings (see Table 2) based on similarities in morphology, life history, and habitat use. These fish primarily consume small invertebrates and are potential prey for larger fish, marine mam- mals, and birds (Buchanan 2006, Duffy \& Beauchamp 2008, Lance et al. 2012, Munsch et al. 2015a). They are mobile and in some cases migratory; thus, it is unlikely to observe the same individuals in replicate surveys. The salmon were almost entirely age-0 transients migrating through the estuary to marine habitats. Puget Sound is also inhabited by demersal predatory fish such as lingcod Ophiodon elongatus and larger sculpins (family Cottidae) that utilize relatively deep nearshore waters (Toft et al. 2007, 2013, Munsch et al. 2014, 2015b). In addition, larger life stages of salmonids (e.g. cutthroat trout O. clarkii, Chinook salmon O. tshawytscha) are the primary predatory fish in the water column.

\section{Surveys}

We assembled a long-term dataset of underwater fish surveys to quantify fine-scale habitat use and behavior of the nearshore fish community (original studies: Toft et al. 2005, 2007, 2009, 2013, Southard et al. 2006, Munsch et al. 2014, 2015b). Snorkel surveys occurred between 2003 and 2013 at 20 sites, and scuba surveys occurred in 2012 at 6 sites (Fig. 1). Snorkel and scuba surveys were conducted by observers at the surface and bottom of the water column, respectively. A total of 817 snorkel and 103 scuba surveys took place April to August to coincide with peak fish presence. Surveys occurred throughout daylight hours, ranging from sunrise to late afternoon (earliest: 05:15 h, latest: 19:40 h).

Surveys followed the same general protocol with minor variations tailored to the original studies. First, observers would swim to a starting position in the water and measure underwater visibility. Surveys only occurred when visibility exceeded $2.5 \mathrm{~m}$ to maximize the accuracy of observations and minimize effects of observers on fish behavior (Toft et al. 2007). Next, observers recorded the depth of the water directly below them using a weighted measuring tape. Observers then surveyed fish while swimming a transect parallel to shore. Snorkel transects ranged from 26 to $75 \mathrm{~m}$ in length and were swum in water $2.25 \pm 1.04 \mathrm{~m}$ (mean $\pm \mathrm{SD}$ ) deep. Scuba transects were $30 \mathrm{~m}$ in length and were swum in water $3.22 \pm$ $0.75 \mathrm{~m}$ deep. Surveys were often conducted at predetermined distances from shore (typically 3 and $10 \mathrm{~m}$ ), and water depths thus varied by tidal height and bottom slope.

Observers quantified the fine-scale behavior and habitat use of fish. The instant fish were encountered, observers recorded the species or finest identi- 


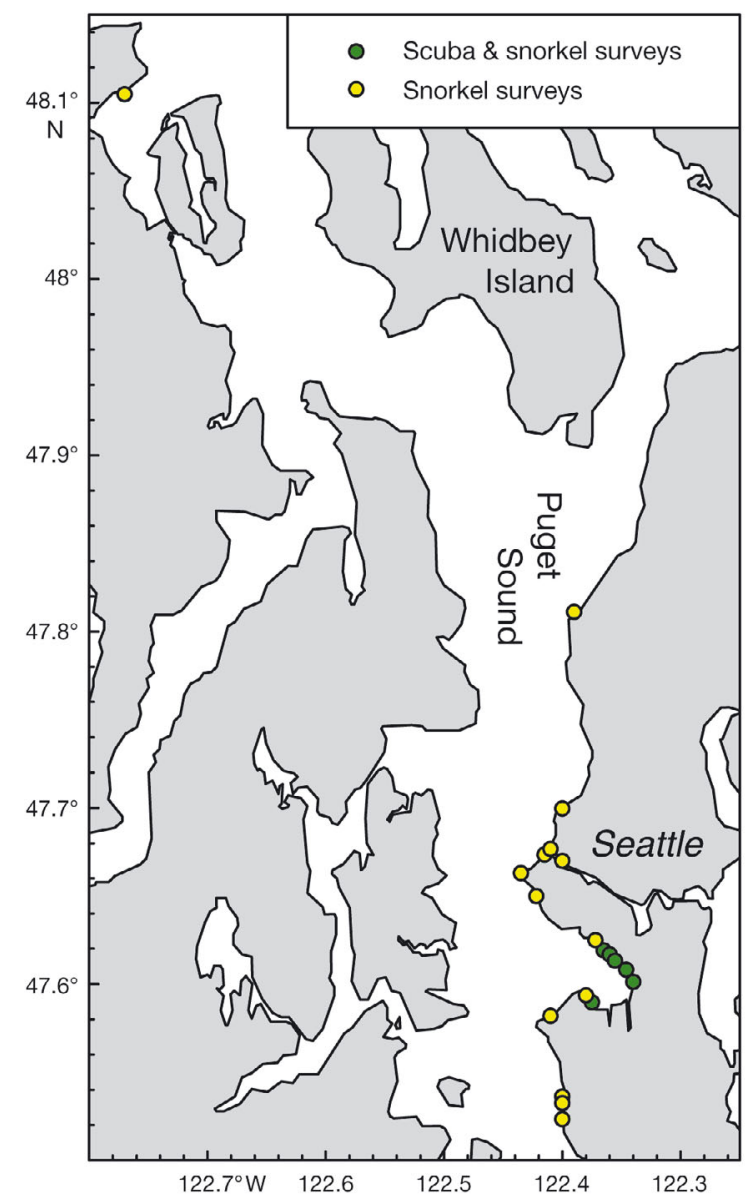

Fig. 1. Study sites in Puget Sound, Washington, USA. Green indicates sites surveyed by snorkelers and scuba divers. Yellow indicates sites surveyed by snorkelers only

fiable taxon of the fish, the visually estimated length of the fish to the nearest $2.5 \mathrm{~cm}$, the number of individuals in the group, and the water column position of the fish. That is, group size and water column position are described as instantaneous metrics of behavior. Group size was estimated in especially large schools by extrapolating counts from a portion of the school and rounding (e.g. to nearest 100). Observers would then continue swimming until the next fish encounter. This set of data was referred to as an observation and was the unit of replication (n) for our study. When fish were not identifiable to the species level, names of lower taxonomic resolution were used to describe their identity (e.g. unidentified salmon, chum/pink salmon). If there was a range of fish lengths in a school, mean length was recorded. For snorkel surveys, water column positions were described in thirds: top, middle, and bottom. Scuba surveys targeted fish near the bottom of the water column and scuba divers described the water column position of fish as $>1 \mathrm{~m}$ from the bottom, $<1 \mathrm{~m}$ from the bottom, or touching the bottom. Fish depths were estimated for snorkel surveys by multiplying the depth of the water by $1 / 6,1 / 2$, and $5 / 6$ for observations at the top, middle, and bottom of the water column, respectively (i.e. it was assumed that fish were centered in the portion of the water column described). Fish depths for scuba surveys were estimated by calculating the water depth / 2, water depth $0.5 \mathrm{~m}$, and taking the entire water depth, for observations $>1 \mathrm{~m},<1 \mathrm{~m}$, and at the bottom, respectively.

\section{Analysis}

Our analysis focused on a subset of the nearshore fish community. The focal community was defined as mid-trophic level species that occupied the water column and were observed by snorkelers a minimum of 35 times. This included the vast majority of all fish observed, and the most abundant taxa excluded were flatfish (order Pleuronectiformes), gunnels (family Pholidae), and sculpin. These taxa rarely occupied the water column and often associated with substrata or algae and may have been under-counted by visual surveys. For some analyses, we included only species that used habitats similarly based on the portion of the water column that they occupied. We termed fish observed at the top of the water-column in $<5 \%$ of snorkel observations as demersal and refer to the remainder as 'water-column-using'. Analyses were conducted in R v.3.2.2 using the lme4, Matching, merTools, and Vegan packages (Bates et al. 2015, Oksanen et al. 2015, R Core Team 2015, Sekhon 2015, Knowles \& Frederick 2016).

We examined habitat partitioning in time and space by visualizing the fish community via nonmetric multidimensional scaling (NMDS). The NMDS was constructed using a Bray-Curtis dissimilarity matrix describing total density estimates (fish counts / [transect length $\times$ horizontal visibility]) for each combination of species, month, and $1 \mathrm{~m}$ estimated depth bin. We used snorkel data only for this NMDS because snorkel surveys were replicated most, and because the snorkelers' field of view was more conducive to surveying the entire water column.

Behavioral comparisons were made using linear mixed effects models and generalized linear mixed models (Zuur et al. 2009). The variables in these models are defined in Table 1. Species were treated as random effects so that models indicated withinspecies trends. Site was also treated as a random effect in models because the slope of the bottom var- 
Table 1. Definitions of parameters used in linear models

\begin{tabular}{|lll|}
\hline Variable & Definition & Type \\
\hline Fish depth & $\begin{array}{c}\text { Vertical distance between } \\
\text { fish and surface }\end{array}$ & Numeric \\
& $\begin{array}{c}\text { Distance between mouth } \\
\text { and tail fork (salmonids) } \\
\text { or caudal peduncle } \\
\text { (non-salmonids) }\end{array}$ & Numeric \\
Group size & $\begin{array}{c}\text { Number of fish swimming } \\
\text { together }\end{array}$ & Numeric \\
Species & $\begin{array}{c}\text { Finest identifiable taxon } \\
\text { of fish }\end{array}$ & Categorical \\
Water column & $\begin{array}{c}\text { Vertical portion of habitat } \\
\text { occupied }\end{array}$ & Categorical \\
Water depth & $\begin{array}{c}\text { Vertical distance between } \\
\text { surface and bottom }\end{array}$ & Numeric \\
& . & \\
\hline
\end{tabular}

ied among sites, which may have influenced the depth distribution of fish. Models examining the response variable of group size always included the fixed effect of fish length because we anticipated a relationship between fish length and group size. When making comparisons of school size among water column positions (but not for fish depth comparisons), scuba observations of fish at the bottom and $<1 \mathrm{~m}$ from the bottom were binned into 1 category because the focal community was rarely observed in contact with the bottom. A linear mixed effects model with a normal distribution and identity link was used for models describing the response variable of fish depth. A generalized linear mixed model with a negative binomial distribution and loglink function was used for models describing the response variable of group size. We attempted to build random slope and intercept models for each comparison. If random slope and intercept models did not converge, we constructed random intercept models. As visual aids, we plotted model fit individually for each species using the same parameters as the community models except omitting the species terms. In rare cases, these models would not converge and we plotted model fit omitting the random parameters. We analyzed snorkel and scuba data separately because depth estimations of fish may not be quantitatively comparable between these methods.

We examined the influence of armoring on the size distribution of fish in the shallowest available habitats. We compared fish at armored sites where intertidal seawalls and riprap created deep habitat adjacent to shore to fish at sites with low-gradient, shallow waters. One of the low-gradient, shallow sites was an artificial habitat bench that created slop- ing habitat adjacent to an urban shoreline (further details in Toft et al. 2013). Of observations along armored shorelines, we only included surveys that took place $3 \mathrm{~m}$ from shore. Of observations along unarmored shorelines, we only included observations that took place in water equal to or shallower than the mean depth of surveys $3 \mathrm{~m}$ from shore at armored sites $(2.39 \mathrm{~m})$. We only included observations at high tide because shoreline waters of armored sites were deepest at high tides. Juvenile salmon, which were only observed by snorkelers, were selected for this comparison because they were known to occupy waters directly adjacent to shore, including areas modified by shoreline infrastructure (Toft et al. 2007).

Supplementally, we qualitatively compared the depth distribution of piscivores to that of the focal community to examine whether predators generally occupied greater depths. Piscivores were uncommon and therefore coarsely defined as individuals $\geq 15 \mathrm{~cm}$ in length and of species that consume fish. We chose this length because cutthroat trout in Puget Sound begin feeding on the focal community at $15 \mathrm{~cm}$ (Duffy \& Beauchamp 2008). To our knowledge, this is the best information available on the size at which a predator feeds on species of the focal community. We regard this examination as supplemental because piscivores constituted a heterogeneous grouping of fish species, preventing a rigorous quantitative analysis of their depth distribution. While acknowledging this limitation, the data were included to provide evidence that shallow waters were inhabited by fewer predators.

\section{RESULTS}

\section{Description of the fish community}

The focal fish community consisted of 13 species that included $99.7 \%$ and $98.9 \%$ of all fish observed by snorkel and scuba divers, respectively (Table 2 , Fig. 2). Fish occasionally swam in schools that were quite large, but the majority of groups were relatively small (quartiles: 1, 2, and 9 individuals [snorkel], 1, 2, and 12 individuals [scuba]). On rare occasions, fish occurred in groups exceeding 1000 individuals ( $0.57 \%$ of observations), and these schools are plotted as 1000s in the figures so that trends among the majority of the data are more interpretable. Forage fish and salmon occurred mostly in the upper part of the water column and were categorized as watercolumn-using. They swam constantly, often in relatively large schools. Surfperch often occurred near the bottom next to substrate or macroalgae and were 
Table 2. Observations (n) and total counts of fish species observed by snorkel and scuba divers, separated by functional group. Total counts are approximate because the sizes of large schools were estimated

\begin{tabular}{|c|c|c|c|c|c|}
\hline Method & Functional group & Species & Scientific name & Observations & Total count \\
\hline \multirow[t]{17}{*}{ Snorkel } & \multirow[t]{7}{*}{ Salmon } & Chinook salmon & \multirow[t]{2}{*}{ Oncorhynchus tshawytscha } & 564 & 5106 \\
\hline & & Chinook/coho salmon & & 309 & 4012 \\
\hline & & Chum salmon & \multirow[t]{2}{*}{ Oncorhynchus keta } & 479 & 25399 \\
\hline & & Chum/pink salmon & & 52 & 12512 \\
\hline & & Coho salmon & Oncorhynchus kisutch & 52 & 230 \\
\hline & & Pink salmon & Oncorhynchus gorbuscha & 106 & 24611 \\
\hline & & Unidentified juvenile salmon & & 62 & 3788 \\
\hline & \multirow[t]{3}{*}{ Forage fish } & Pacific herring & Clupea pallasii & 61 & 27362 \\
\hline & & Surf smelt & Hypomesus pretiosus & 35 & 9768 \\
\hline & & Sand lance & Ammodytes hexapterus & 70 & 42757 \\
\hline & \multirow[t]{5}{*}{ Surfperch } & Kelp perch & Brachyistius frenatus & 141 & 347 \\
\hline & & Pile perch & Rhacochilus vacca & 1169 & 4020 \\
\hline & & Shiner perch & Cymatogaster aggregata & 1121 & 142312 \\
\hline & & Striped seaperch & Embiotoca lateralis & 1925 & 4242 \\
\hline & & Unknown perch & & 79 & 261 \\
\hline & \multirow[t]{2}{*}{ Other } & Three-spined stickleback & Gasterosteus aculeatus & 73 & 893 \\
\hline & & Tubesnout & Aulorhynchus flavidus & 296 & 9349 \\
\hline \multirow[t]{5}{*}{ Scuba } & \multirow[t]{4}{*}{ Surfperch } & Kelp perch & Brachyistius frenatus & 101 & 196 \\
\hline & & Pile perch & Rhacochilus vacca & 13 & 21 \\
\hline & & Shiner perch & Cymatogaster aggregata & 88 & 1941 \\
\hline & & Striped seaperch & Embiotoca lateralis & 171 & 281 \\
\hline & Other & Tubesnout & Aulorhynchus flavidus & 227 & 7529 \\
\hline
\end{tabular}

categorized as demersal. They swam in punctuated movements and, except for shiner perch, occurred in small schools. Tubesnout were categorized as demersal, occasionally occurred in relatively large groups, and swam in punctuated movements. Stickleback were categorized as water-column-using, occurred in relatively small schools, and swam in punctuated movements. In addition to these fish, 16 species of piscivores were present. The piscivorous status for most of these fish could be corroborated by literature on their diets or the diets of closely related species (greenling: Reisewitz et al. 2006; lingcod: Beaudreau
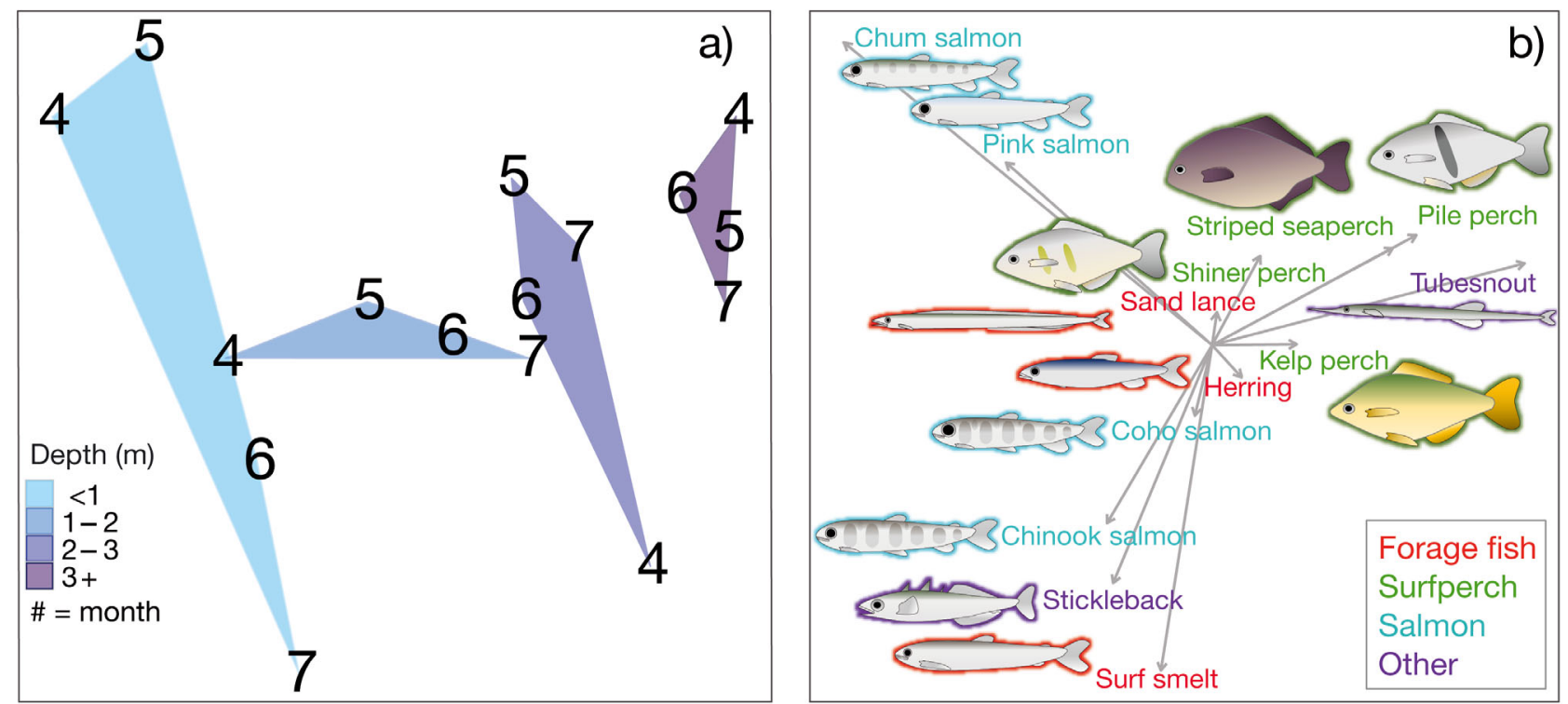

Fig. 2. (a,b) Nonmetric multidimensional scaling plots of the fish assemblage. (a) Each point indicates a unique combination of depth bin (color bar) and month of the year (4: April to 7: July). Polygons are shaded to connect observations at the same depth observed over time. (b) Vectors indicate increasing gradients of species densities in ordination space. The outline color of fish illustrations corresponds to the functional grouping of the fish (Table 2) 
\& Essington 2007; ratfish and sculpin: Reum \& Essington 2008; rockfish: Brodeur et al. 1987; salmonids: Duffy \& Beauchamp 2008). Piscivores were distributed in deep waters relative to the focal community (see Fig. S1 \& Table S1 in the Supplement at www. int-res.com/articles/suppl/m557p001_supp.pdf).

\section{Context-dependent behavior and habitat partitioning}

Snorkel observations indicated that larger fish occupied significantly greater depths (Table 3, Fig. 3). A positive or neutral trend of fish size relative to depth was detected in all species except stickleback and tubesnout, and the most positive trends occurred in salmon and surfperch. Scuba divers also observed larger fish with increasing depths, but this was not statistically significant (Table 3, Fig. 3). As observed by scuba divers, larger surfperch tended to occupy greater depths, but larger tubesnout did not.

The size distribution of juvenile salmon was significantly different along armored shorelines compared to shorelines with low-gradient, shallow waters (Fig. 4; bootstrap Kolmogorov-Smirnov test, p < 0.0001). At sites with low-gradient shallow waters, the size distribution was skewed toward smaller fish, whereas larger fish were proportionally more abundant along armored shorelines.
Snorkel and scuba observations indicated that larger individuals occurred in significantly smaller group sizes (Table 3, Fig. 5). This trend was consistent for most species, except coho salmon and pink salmon observed by snorkelers, and kelp perch and pile perch observed by scuba divers. A decline in school size with increasing fish size was most apparent in species that occurred in a range of sizes and had large maximum school sizes.

Snorkel observations of water column-using species indicated that significantly larger schools of fish occurred in deeper waters (Table 3, Fig. 6). We observed this trend for most species, excluding surf smelt and stickleback. Salmon in particular were often observed in shallow waters and exhibited a strong positive relationship between school size and water depth.

Snorkel and scuba observations of demersal species indicated that these fish occurred in significantly larger schools when they were away from the bottom of the water column (Table 3, Fig. 7). This trend was consistent among all species except pile perch, and was most apparent in shiner perch and tubesnout.

Fish partitioned nearshore waters in space and time. There was separation of habitats among species by depth and month (Fig. 2). Surface waters were occupied predominantly by chum and pink salmon in April and May, and by Chinook salmon, coho salmon, forage fish, and stickleback in June and July. There

Table 3. Parameter estimates and summary statistics of linear models. Vertical bars indicate random slope parameters separating random terms (right) from their interacting fixed terms (left), otherwise random effects were treated as intercepts only. WCP: water-column position

\begin{tabular}{|c|c|c|c|c|c|c|c|}
\hline $\begin{array}{c}\text { Response } \\
\text { variable }\end{array}$ & Method & Fish group & Parameter & Estimate & $\mathrm{SE}$ & $\mathrm{p}$ & Random effect \\
\hline \multirow{4}{*}{ Fish depth } & \multirow[t]{2}{*}{ Snorkel } & \multirow[t]{2}{*}{ All } & Intercept & 0.772955 & 0.161139 & $3.99 \times 10^{-5}$ & Length I Species \\
\hline & & & Fish length & 0.032932 & 0.008184 & 0.000704 & Length I Site \\
\hline & \multirow[t]{2}{*}{ Scuba } & \multirow[t]{2}{*}{ All } & Intercept & 2.39506 & 0.14086 & $4.28 \times 10^{-5}$ & Length I Species \\
\hline & & & Fish length & 0.01797 & 0.01513 & 0.306 & Length I Site \\
\hline \multirow[t]{13}{*}{ Group size } & \multirow[t]{2}{*}{ Snorkel } & \multirow[t]{2}{*}{ All } & Intercept & 4.48705 & 0.61696 & $3.52 \times 10^{-13}$ & Length I Species \\
\hline & & & Fish length & -0.14803 & 0.03512 & $2.50 \times 10^{-5}$ & Site \\
\hline & \multirow[t]{2}{*}{ Scuba } & \multirow[t]{2}{*}{ All } & Intercept & 3.32411 & 1.0276 & $1.22 \times 10^{-3}$ & Length I Species \\
\hline & & & Fish length & -0.11428 & 0.04484 & 0.0108 & Site \\
\hline & \multirow[t]{3}{*}{ Snorkel } & \multirow{3}{*}{$\begin{array}{l}\text { Water- } \\
\text { column-using }\end{array}$} & Intercept & 4.74119 & 0.49120 & $2.00 \times 10^{-5}$ & Water depth I Species \\
\hline & & & Water depth & 0.35854 & 0.08854 & $5.13 \times 10^{-5}$ & Site \\
\hline & & & Fish length & -0.19559 & 0.01739 & $2.00 \times 10^{-16}$ & \\
\hline & \multirow[t]{3}{*}{ Snorkel } & \multirow[t]{3}{*}{ Demersal } & Intercept & 2.455709 & 0.623607 & $8.22 \times 10^{-5}$ & WCP I Species \\
\hline & & & $\begin{array}{l}\text { WCP (baseline: } \\
\text { bottom) }\end{array}$ & 0.518641 & 0.172526 & $2.65 \times 10^{-3}$ & Site \\
\hline & & & Fish length & -0.032743 & 0.005381 & $1.16 \times 10^{-9}$ & \multirow{4}{*}{$\begin{array}{l}\text { WCP I Species } \\
\text { Site }\end{array}$} \\
\hline & \multirow[t]{3}{*}{ Scuba } & \multirow[t]{3}{*}{ Demersal } & Intercept & 2.15032 & 0.07217 & $2.89 \times 10^{-3}$ & \\
\hline & & & $\begin{array}{l}\text { WCP (baseline: } \\
\text { bottom) }\end{array}$ & 0.38036 & 0.15526 & 0.0143 & \\
\hline & & & Fish length & -0.03614 & 0.02267 & 0.11096 & \\
\hline
\end{tabular}




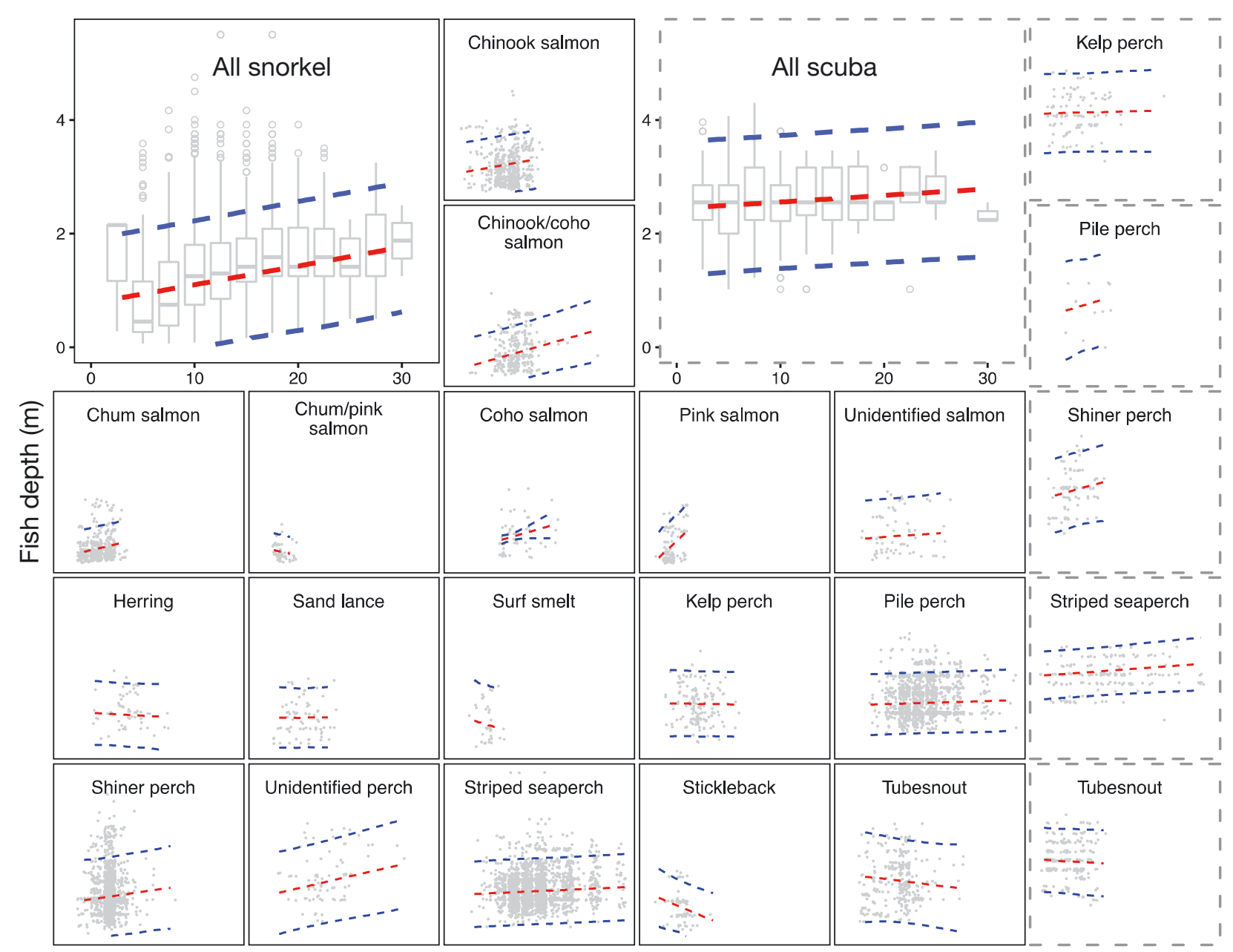

Fish length $(\mathrm{cm})$

Fig. 3. Fish depth vs. fish size as observed by snorkelers (solid panels) and scuba divers (dashed panels). Within observation method, panel axes are shown on the same scale. Boxplots: upper and lower hinges: first and third quartiles; mid-line: median; whiskers: points within $1.5 \times$ interquartile range; dots represent data outside of $1.5 \times$ interquartile range. Red and blue lines indicate values predicted by models and $95 \%$ confidence intervals, respectively

was little temporal variation in abundances of surfperch and tubesnout, which occupied greater depths. Thus, there was seasonal variation in fish assemblage composition near the surface, but the assemblage remained stratified by depth.

\section{DISCUSSION}

We used a long-term dataset of in situ observations to quantify in unprecedented detail the fine-scale habitat use and context-dependent behavior of a nearshore fish community. Our major findings were documentation of (1) fine-scale patterns of habitat use suggestive of process-based nursery functions directly adjacent to shore, (2) context-dependent behaviors consistent with decisions to balance safety from pre- dation with other life-history objectives, and (3) seasonality and fine-scale depth as simultaneous axes of habitat partitioning. These findings have management implications for protecting process-based nursery functions in shallow areas that have only recently been appreciated (Sheaves et al. 2015). They also fill empirical gaps in our understanding of in situ fish ecology. Most fundamentally, our study underscores the limited knowledge about complexity in aquatic ecosystems, including systems facing considerable anthropogenic threats. Thus, it supports current arguments for a renewed focus on natural history in these systems that will ultimately benefit ecology and conservation (Tewksbury et al. 2014, Able 2016).

Our observation that larger fish utilized deeper habitats suggested that shallow sloping areas supported a continuum of habitat functions that bene- 


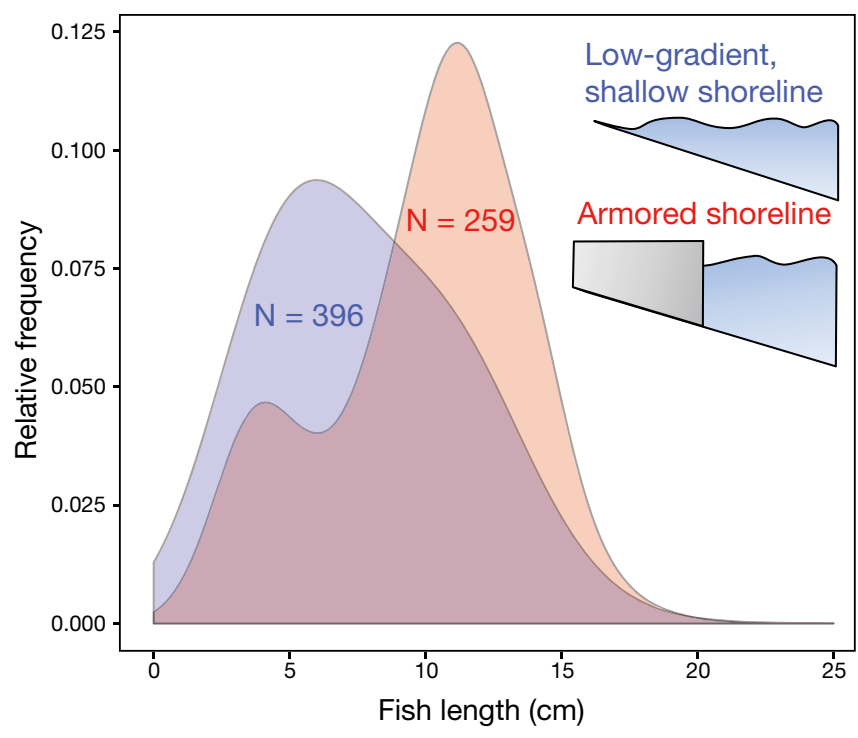

Fig. 4. Size distribution of juvenile salmon Oncorhynchus spp. compared between the shallowest available habitats in low-gradient, shallow shorelines and armored shorelines

fited different fish sizes. Animals often utilize safe habitats to the extent that avoiding predation is in balance with other life history objectives (Lima \& Dill 1990). Many studies have found that predation risk in nearshore habitats increases with increasing depth (e.g. McIvor \& Odum 1988, Ruiz et al. 1993, Linehan et al. 2001, but see Baker \& Sheaves 2007) and that fish length increases with depth (Macpherson \& Duarte 1991, Ruiz et al. 1993). This is thought to drive Heincke's Law (developed from Heincke 1913) whereby smaller fish occupy shallower waters because they are more vulnerable to predation (Sogard 1997, Linehan et al. 2001), and was consistent with our observations of few potential piscivores in relatively shallow water. In addition to lowering mortality, shallow areas may also benefit fish through sublethal effects of protected areas. For example, tethering experiments found no relationship between depth and predation despite the focal fish aggregating in shallow areas (Baker \& Sheaves 2007). The authors discussed that fish may utilize shallower areas so that they can allocate less time and energy into antipredator behaviors (e.g. evasion, vigilance) rather than necessarily to decrease probability of mortality. We observed ontogenetic habitat shifts to greater depths that may have allowed juveniles to balance the benefits of feeding with the costs of predation risk (Sheaves et al. 2015): small juveniles may benefit most from the lack of predators at shallow depths whereas larger, less vulnerable juveniles may trade this benefit for larger foraging areas and different prey fields in deeper waters. This is consistent with the development of Chinook salmon that move from nearshore to offshore habitats and shift prey from insects and amphipods to crab larvae and fish (Duffy et al. 2010). We also observed that stickleback, which are relatively small as adults, utilized shallower areas at all sizes, suggesting that shallow areas may benefit smaller species throughout their life histories. Thus, shallow sloping waters were a potentially critical component of nearshore habitats, an important consideration given losses of this habitat type in developed landscapes.

Ontogenetic habitat shifts occurred close to shore, and shoreline armoring may compromise this nursery function. A relationship between fish length and depth was only detected by snorkelers, who were able to observe fish closer to shore than scuba divers. Thus, a major portion of ontogenetic habitat shifts may occur in the shallowest waters directly adjacent to shore. In addition, shoreline armoring appeared to alter the fish distribution in the shallowest available habitats. Smaller salmon were proportionally more abundant along shorelines with shallow habitat compared to the deeper waters along armored shorelines, suggesting that smaller juveniles select shallower habitats when they are available. Armoring may compromise nursery functions by forcing smaller juveniles to occupy deeper habitats that are dangerous or offer inappropriate prey sources, i.e. by disrupting ontogenetic habitat shifts and providing suboptimal food/predation tradeoffs (Sheaves et al. 2015). Managers may therefore conserve nursery functions of shallow ecosystems by protecting shallow sloping areas adjacent to shore.

Schooling may further mediate tradeoffs between predation risk and other objectives. We observed darker-colored demersal fish schooling in larger groups when they occurred away from camouflage at the bottom of the water column. Visual piscivores typically rely on contrast to detect prey (Breck 1993), and schooling may have allowed demersal fish to offset predation risk when they were away from camouflaging backdrops. We also observed that smaller fish occurred in larger schools, and schooling may primarily benefit smaller, more vulnerable fish through diluting risk of capture, increasing predator vigilance, or confusing predators (Pitcher \& Parrish 1993, Sogard 1997). We must also consider that this trend may have been influenced by the size distribution of species because fish tend to school with fish of the same size (Hoare et al. 2000). Such an influence would manifest most in chum and pink salmon: small individuals were probably most abundant because 


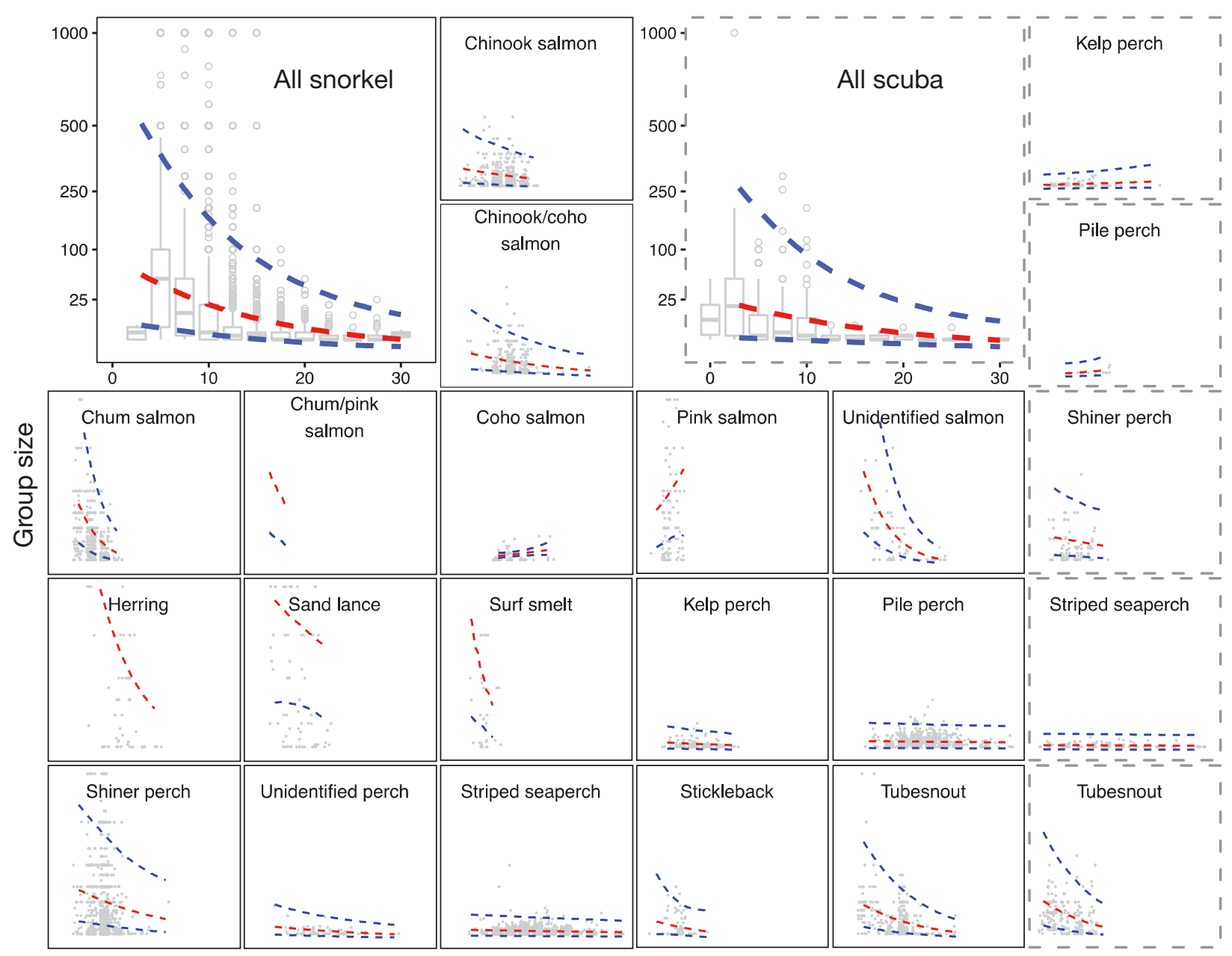

Fish length $(\mathrm{cm})$

Fig. 5. Group size vs. fish length as observed by snorkelers (solid panels) and scuba divers (dashed panels). Within observation method, panel axes are shown on the same scale. See Fig. 3 for box-plot and confidence interval definitions

these species immigrate over a short period of time, grow rapidly, and suffer high mortality (Quinn 2005). However, smaller tubesnout and surfperch in particular were comparatively rare and schooled in large groups, consistent with these fish schooling to offset vulnerability to predators. Overall, our observations were consistent with schooling as a context-dependent behavior that mediates predation risk.

Schooling may allow fish to maximize habitat benefits. Water-column-using fish formed larger schools in deeper water, potentially allowing them to occupy patches where safety was lower but foraging potential was greater. For example, schooling may facilitate forays by planktivorous forage fish (Penttila 2007) or juvenile salmon (Munsch et al. 2015a) into deeper waters where plankton are more abundant and foraging spaces are larger. Others have demonstrated an analogous scenario in aquaria whereby fish in larger schools forgo predator refuge to occupy exposed foraging patches (Magurran \& Pitcher 1983). We must also consider that relationships between depth and school size may be influenced by the spatial constraints of shallower water, in which case fish may directly trade off the safety of shallow waters for that of larger groups. Demersal fish may have also benefited from schooling if it allows them to mitigate risk when locating epibenthic prey patches from more effective vantage points in the water column, and because group sensing allows fish to locate resources more quickly (Berdahl et al. 2013). These fish may school when they risk predator detection by searching for prey from the water column, and then disperse to minimize competition when feeding on epibenthos, similar to the behavior of fish exposed to variable predator cues and food in aquaria (Hoare et al. 2004). Overall, schooling appeared to be a con- 


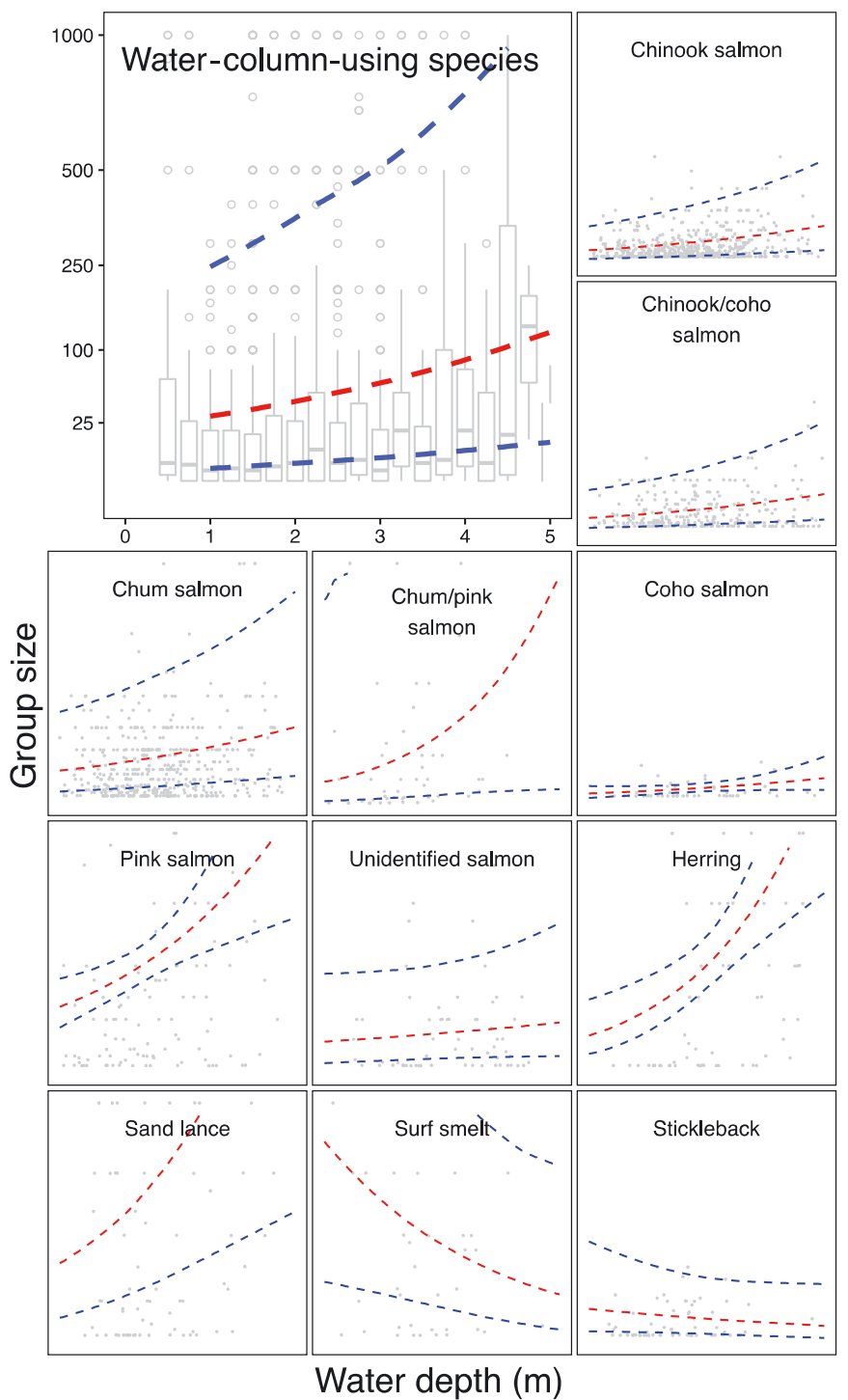

Fig. 6. Group size vs. water depth of water-column-using species as observed by snorkelers. Panel axes are shown on the same scale. See Fig. 3 for box plot and confidence interval definitions

text-dependent antipredator behavior, a concept that has received considerable research attention yet has rarely been examined in situ.

Schooling is typically investigated in pelagic environments, but this behavior may be similarly beneficial in shallow waters. Theoretically, an optimum school size exists for fish in a given scenario that balances the costs and benefits of grouping (Rieucau et al. 2015b). However, in massive pelagic schools, optimum school sizes are probably rarely realized due to complex dynamics of splitting and joining groups, and because substantial sensory capabilities of fish would be required to determine the exact size of larger groups (Fernö et al. 1998, Rieucau et al. 2015b). In addition, an individual or undersized school of fish may behave optimally by joining another group regardless of its size; thus, groups may increase to suboptimal sizes as others join to their own benefit (sensu Sibly 1983). This choice is presumably most constrained in environments where conspecific encounters are rare and unpredictable, creating a greater expected cost for an individual to forgo joining a group of any size. We hypothesize that, in contrast to pelagic waters, relatively linear nearshore waters benefit fish through predictable conspecific encounters that allow fish greater choice over their group sizes, ultimately resulting in maximal habitat use. Results from our focal fish community support this hypothesis: forage fish were the most pelagic of the functional groups and formed the largest schools. Thus, connectivity may be important in shallow habitats to facilitate predictable conspecific encounters that enable fish to school in more optimal school sizes.

We observed a spatiotemporal structure to the fish community that was suggestive of broader ecological concepts. The first concept was time and space as simultaneous axes of habitat partitioning. Time is an important axis of resource partitioning that may allow species that use the same habitats to coexist by minimizing competition (Kronfeld-Schor \& Dayan 2003). For example, chum and pink salmon may minimize competition with other species that forage in the water column by inhabiting nearshore systems earlier in the year. Temporal habitat partitioning in nearshore waters may be widespread given that juveniles often use habitats temporarily as they develop (Nagelkerken et al. 2015). One management application of spatiotemporal habitat partitioning is that artificial propagation programs may aim to release juvenile fish at times that minimize overlap with competing species. Furthermore, temporal habitat partitioning may enhance the stability of water-column-using fish as a prey source. The watercolumn-using fish group was present longer and had more stable abundances than the individual, transient species that comprised it (sensu Schindler et al. 2015). Thus, temporal habitat partitioning may benefit predators through lower variation in overall prey availability, and managers may conserve these benefits by protecting species that partition similar habitats in time as a unit. An additional ecological concept was that these fish may be adapted to minimize different parts of the predation process (sensu Heithaus \& Dill 2006). Demersal species were slow, deep-bodied, and colored similar to substrate and algae backdrops. Species that occupied the water 

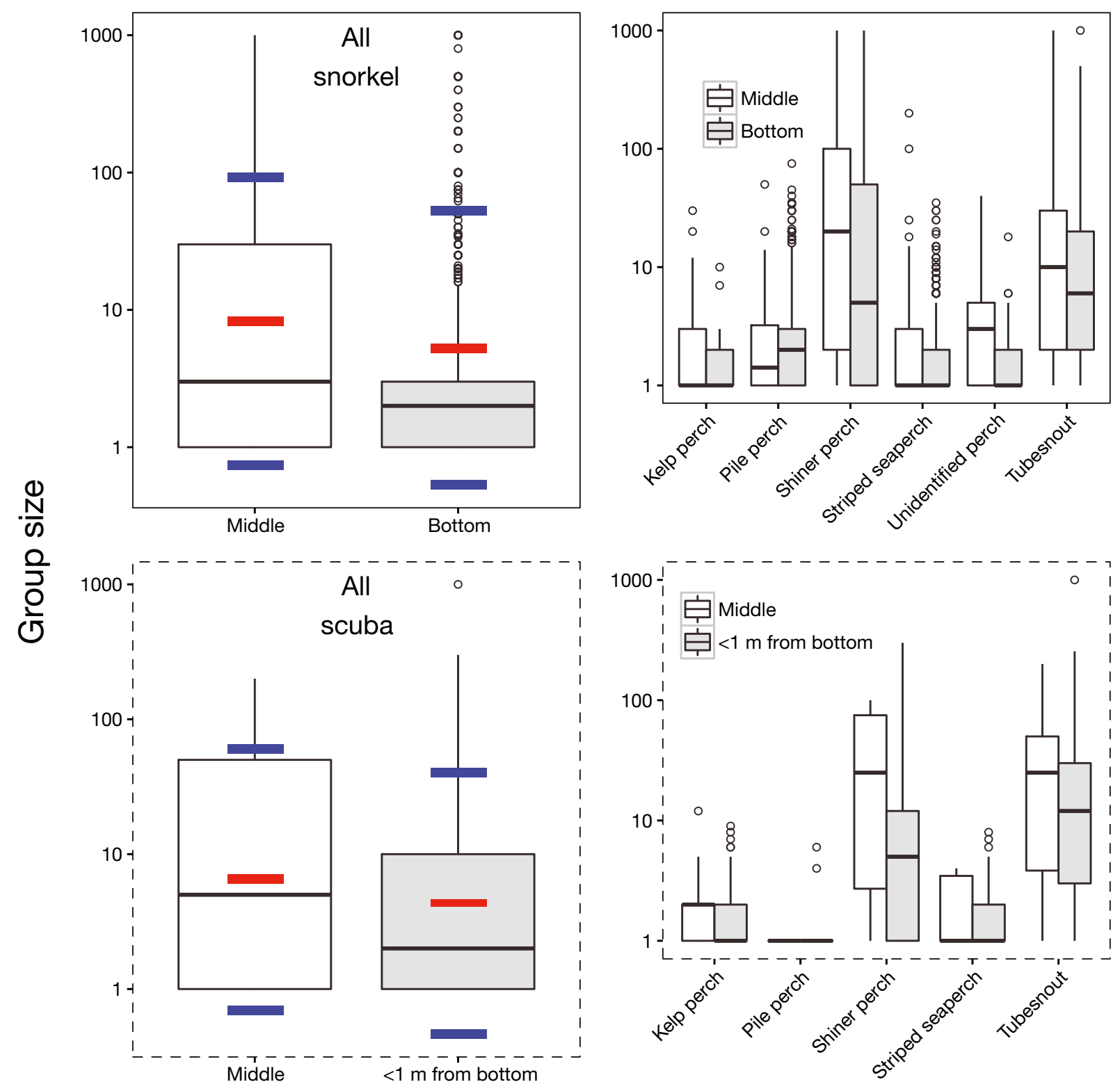

Fig. 7. Group size vs. water column position for demersal species as observed by snorkelers (solid panels) and scuba divers (dashed panels). See Fig. 3 for box plot and confidence interval definitions

column were faster, spindle-shaped, and silvery. Thus, demersal species may primarily be adapted to minimize predator detection while species that used the water column may be more adapted to evade capture. Overall, there was evidence that the fine-scale depth distribution and seasonality of the nearshore community were potentially important natural history adaptations.

Limitations of our study should be considered in the interpretation of our findings. First, we conducted an analysis that combined observational studies and did not measure predation risk directly. We infer fac- tors that influence predation risk from other studies (e.g. McIvor \& Odum 1988, Sogard 1997), and our work would benefit from further manipulative approaches that directly quantify how behaviors mediate cost/benefit tradeoffs. We also inferred piscivory from fish length using a study of diets in one predatory species (Duffy \& Beauchamp 2008), yet lengthpiscivory relationships are likely to vary among species. Further, smaller fish including species not considered major piscivores may exert great predation pressure on juvenile fish if these predators are abundant (Baker \& Sheaves 2009). Thus, the focal commu- 
nity and their predators may overlap to a greater extent than we present here, and our study would have benefited from a greater understanding of the diets of all species present. Next, our study was conducted in an urbanized setting. Many sites had been modified by shoreline development and their shallow areas were truncated by shoreline armoring. Consequently, our study may underestimate the magnitude of ontogenetic habitat shifts from shallow to deep waters because fish sometimes lacked accesses to shallow areas. In addition, the animal assemblage probably differed from historical conditions. Predator encounters influence the decision-making of consumers (Lima \& Dill 1990), and potential changes to the predator assemblage could have affected the behaviors we observed. In addition, we surveyed fish only during daylight hours, and diel cycles are well known to influence the behavior of fish, including sizes of schools in shallow waters (Rieucau et al. 2015a). Finally, we estimated some measurements (e.g. fish length, school size), and thus trends in this study are more appropriately interpreted in relative rather than absolute terms. These factors are potential avenues for further research, but are beyond the scope of our opportunistic study.

In conclusion, fish behaved in ways that would maximize habitat use and avoid predation, and they partitioned shallow habitats in time and space. Juvenile behaviors were indicative of their use of shallow waters as nursery habitat, potentially reflecting the habitat's provision of predator refuge, ontogenetic habitat shifts, and appropriate food/predation risk tradeoffs (Beck et al. 2001, Sheaves et al. 2015). These functions may be diminished by changes to shallow ecosystems. It is of particular concern that shallow waters and their associated nursery functions (e.g. ontogenetic habitat shifts) are disappearing globally due to shoreline armoring (Bulleri \& Chapman 2010) and coastal squeeze whereby rising sea levels encroach on built shorelines (Doody 2004). It is also concerning that the connectivity of shallow habitats and their associated benefits (e.g. access to appropriate habitats, frequent conspecific encounters) are threatened by habitat elimination and behavioral barriers such as shading from large piers (Able et al. 2013, Munsch et al. 2014, Ono \& Simenstad 2014). However, some of the functions of degraded ecosystems can be repaired and the benefits of habitat improvements need not be limited to fish. For instance, conventional shoreline designs of impervious surfaces place society at risk because they are incompatible with a future of sea level rise. It is therefore advantageous for city planners to pro- tect flood-prone areas by creating or restoring shallow ecosystems rather than armoring shorelines (Temmerman et al. 2013). Also, urban waterfronts can be designed that provide corridors of sloping shallow areas and reduce the shading impacts of piers without sacrificing waterfront utility to people (Toft et al. 2013, Cordell et al. in press). Ultimately, by understanding the natural history of shallow-water fish communities, we may identify and account for critical habitat functions in order to manage shoreline features that benefit fish and people.

Acknowledgements. Surveys were conducted by members of the University of Washington Wetland Ecosystem Team. Funding for the studies combined for this investigation was provided by the City of Seattle, Estuary and Salmon Restoration Program, King Conservation District, Seattle Art Museum, Seattle Department of Transportation, Seattle Public Utilities, Washington Department of Fish and Wildlife, Washington State Department of Transportation, and WRIA 9. S.H.M. was additionally supported by a National Science Foundation Graduate Research Fellowship (DGE 1256082). The manuscript was improved by helpful critiques from 4 anonymous reviewers.

\section{LITERATURE CITED}

Able KW (2016) Natural history: an approach whose time has come, passed, and needs to be resurrected. ICES J Mar Sci (in press), doi:10.1093/icesjms/fsw049

Able KW, Grothues TM, Kemp IM (2013) Fine-scale distribution of pelagic fishes relative to a large urban pier. Mar Ecol Prog Ser 476:185-198

> Alexander RD (1974) The evolution of social behavior. Annu Rev Ecol Syst 5:325-383

> Baker R, Sheaves M (2007) Shallow-water refuge paradigm: conflicting evidence from tethering experiments in a tropical estuary. Mar Ecol Prog Ser 349:13-22

> Baker R, Sheaves M (2009) Overlooked small and juvenile piscivores dominate shallow-water estuarine "refuges" in tropical Australia. Estuar Coast Shelf Sci 85:618-626

Bates D, Maechler M, Bolker B, Walker S (2015) Fitting linear mixed-effects models using lme4. J Stat Softw 67: $1-48$

Beaudreau AH, Essington TE (2007) Spatial, temporal, and ontogenetic patterns of predation on rockfishes by lingcod. Trans Am Fish Soc 136:1438-1452

Beck MW, Heck KL, Able KW, Childers DL and others (2001) The identification, conservation, and management of estuarine and marine nurseries for fish and invertebrates: a better understanding of the habitats that serve as nurseries for marine species and the factors that create site-specific variability in nursery quality will improve conservation and management of these areas. Bioscience 51:633-641

Berdahl A, Torney CJ, Ioannou CC, Faria JJ, Couzin ID (2013) Emergent sensing of complex environments by mobile animal groups. Science 339:574-576

$>$ Breck JE (1993) Foraging theory and piscivorous fish: Are forage fish just big zooplankton? Trans Am Fish Soc 122: 902-911 
Brodeur RD, Lorz HV, Pearcy WG (1987) Food habits and dietary variability of pelagic nekton off Oregon and Washington, 1979-1984. NOAA Tech Rep NMFS 57

Buchanan JB (2006) Nearshore birds in Puget Sound. Puget Sound Nearshore Partnership, Seattle, WA

Bulleri F, Chapman MG (2010) The introduction of coastal infrastructure as a driver of change in marine environments. J Appl Ecol 47:26-35

Cordell JR, Toft JD, Munsch SH, Goff M (in press) Benches, beaches, and bumps: how habitat monitoring and experimental science can inform urban seawall design. In: Bilkovic DM, Mitchell MR, Toft JD, La Peyre MK (eds) Living shorelines: the science and management of naturebased coastal protection. CRC Press, Boca Raton, FL

> Dahlgren CP, Kellison GT, Adams AJ, Gillanders BM and others (2006) Marine nurseries and effective juvenile habitats: concepts and applications. Mar Ecol Prog Ser 312:291-295

Dill LM (1983) Adaptive flexibility in the foraging behavior of fishes. Can J Fish Aquat Sci 40:398-408

Doody JP (2004) 'Coastal squeeze'-an historical perspective. J Coast Conserv 10:129-138

> Duffy EJ, Beauchamp DA (2008) Seasonal patterns of predation on juvenile Pacific salmon by anadromous cutthroat trout in Puget Sound. Trans Am Fish Soc 137:165-181

Duffy EJ, Beauchamp DA, Sweeting RM, Beamish RJ, Brennan JS (2010) Ontogenetic diet shifts of juvenile Chinook salmon in nearshore and offshore habitats of Puget Sound. Trans Am Fish Soc 139:803-823

Fernö A, Pitcher TJ, Melle W, Nøttestad L, Mackinson S, Hollingworth C, Misund OA (1998) The challenge of the herring in the Norwegian sea: making optimal collective spatial decisions. Sarsia 83:149-167

Grand TC, Dill LM (1999) The effect of group size on the foraging behaviour of juvenile coho salmon: reduction of predation risk or increased competition? Anim Behav 58: 443-451

Heincke F (1913) Untersuchungen über die Scholle. Generalbericht. I. Schollenfischerei und Schonmassregeln. Vorläufige kurze Übersicht über die wichtigsten Ergebnisse des Berichts. Rapp P-V Reun Cons Int Explor Mer $16: 1-70$

> Heithaus MR, Dill LM (2006) Does tiger shark predation risk influence foraging habitat use by bottlenose dolphins at multiple spatial scales? Oikos 114:257-264

> Hoare DJ, Krause J, Peuhkuri N, Godin JG (2000) Body size and shoaling in fish. J Fish Biol 57:1351-1366

> Hoare DJ, Couzin ID, Godin JG, Krause J (2004) Contextdependent group size choice in fish. Anim Behav 67: 155-164

Knowles J, Frederick C (2016) merTools: Tools for Analyzing Mixed Effect Regression Models. R package version 0.2.1, http://CRAN.R-project.org/package=merTools

Kronfeld-Schor N, Dayan T (2003) Partitioning of time as an ecological resource. Annu Rev Ecol Evol Syst 34:153-181

- Lance MM, Chang WY, Jeffries SJ, Pearson SF, AcevedoGutiérrez A (2012) Harbor seal diet in northern Puget Sound: implications for the recovery of depressed fish stocks. Mar Ecol Prog Ser 464:257-271

> Lima SL, Dill LM (1990) Behavioral decisions made under the risk of predation: a review and prospectus. Can J Zool 68:619-640

Linehan JE, Gregory RS, Schneider DC (2001) Predation risk of age-0 cod (Gadus) relative to depth and substrate in coastal waters. J Exp Mar Biol Ecol 263:25-44
Macpherson E, Duarte CM (1991) Bathymetric trends in demersal fish size: Is there a general relationship? Mar Ecol Prog Ser 71:103-112

Magurran AE, Pitcher TJ (1983) Foraging, timidity and shoal size in minnows and goldfish. Behav Ecol Sociobiol 12: $147-152$

McIvor CC, Odum WE (1988) Food, predation risk, and microhabitat selection in a marsh fish assemblage. Ecology 69:1341-1351

> Munsch SH, Cordell JR, Toft JD, Morgan EE (2014) Effects of seawalls and piers on fish assemblages and juvenile salmon feeding behavior. N Am J Fish Manag 34:814-827

> Munsch SH, Cordell JR, Toft JD (2015a) Effects of seawall armoring on juvenile Pacific salmon diets in an urban estuarine embayment. Mar Ecol Prog Ser 535:213-229

Munsch SH, Cordell JR, Toft JD (2015b) Effects of shoreline engineering on shallow subtidal fish and crab communities in an urban estuary: a comparison of armored shorelines and nourished beaches. Ecol Eng 81:312-320

> Nagelkerken I, Sheaves M, Baker R, Connolly RM (2015) The seascape nursery: a novel spatial approach to identify and manage nurseries for coastal marine fauna. Fish Fish 16:362-371

Oksanen J, Guillaume Blanchet F, Kindt R, Legendre P and others (2015) Vegan: Community Ecology Package. R package version 2.3-2. https://cran.r-project.org/package= vegan

> Ono K, Simenstad CA (2014) Reducing the effect of overwater structures on migrating juvenile salmon: an experiment with light. Ecol Eng 71:180-189

Paterson AW, Whitfield AK (2000) Do shallow-water habitats function as refugia for juvenile fishes? Estuar Coast Shelf Sci 51:359-364

Penttila D (2007) Marine forage fishes in Puget Sound. Puget Sound nearshore partnership report No. 2007-03. Seattle District, U.S. Army Corps of Engineers, Seattle, WA

Pitcher T, Parrish JK (1993) Antipredator functions of shoaling. In: Pitcher $\mathrm{T}$ (ed) The behaviour of teleost fishes. Croom Helm, London, p 229-268

Quinn TP (2005) The behavior and ecology of Pacific salmon and trout. University of Washington Press, Seattle, WA

R Core Team (2015) R: a language and environment for statistical computing. R Foundation for Statistical Computing, Vienna

> Reisewitz SE, Estes JA, Simenstad CA (2006) Indirect food web interactions: sea otters and kelp forest fishes in the Aleutian archipelago. Oecologia 146:623-631

$>$ Reum JCP, Essington TE (2008) Seasonal variation in guild structure of the Puget Sound demersal fish community. Estuaries Coasts 31:790-801

> Rieucau G, Boswell KM, Kimball ME, Diaz G, Allen DM (2015a) Tidal and diel variations in abundance and schooling behavior of estuarine fish within an intertidal salt marsh pool. Hydrobiologia 753:149-162

> Rieucau G, Fernö A, Ioannou CC, Handegard NO (2015b) Towards of a firmer explanation of large shoal formation, maintenance and collective reactions in marine fish. Rev Fish Biol Fish 25:21-37

Ruiz GM, Hines AH, Posey MH (1993) Shallow water as a refuge habitat for fish and crustaceans in non-vegetated estuaries: an example from Chesapeake Bay. Mar Ecol Prog Ser 99:1-16

Schindler DE, Armstrong JB, Reed TE (2015) The portfolio concept in ecology and evolution. Front Ecol Environ $13: 257-263$ 
Sekhon JS (2015) Matching: multivariate and propensity score matching with balance optimization. R package version 4.9-2, https://cran.r-project.org/package=Matching

Sheaves M, Baker R, Johnston R (2006) Marine nurseries and effective juvenile habitats: an alternative view. Mar Ecol Prog Ser 318:303-306

Sheaves M, Baker R, Nagelkerken I, Connolly RM (2015) True value of estuarine and coastal nurseries for fish: incorporating complexity and dynamics. Estuaries Coasts 38:401-414

Sibly RM (1983) Optimal group size is unstable. Anim Behav 31:947-948

Sogard SM (1997) Size-selective mortality in the juvenile stage of teleost fishes: a review. Bull Mar Sci 60: 1129-1157

Southard SL, Thom RM, Williams GD, Toft JD and others (2006) Impacts of ferry terminals on juvenile salmon movements along Puget Sound shorelines. Washington State Department of Transportation, Olympia, WA

Temmerman S, Meire P, Bouma TJ, Herman PM, Ysebaert T, De Vriend HJ (2013) Ecosystem-based coastal defence in the face of global change. Nature 504(7478):79-83

Tewksbury JJ, Anderson JG, Bakker JD, Billo TJ and others (2014) Natural history's place in science and society.

Editorial responsibility: Jana Davis,

Annapolis, Maryland, USA
Bioscience 64:300-310

Toft JD, Cordell JR, Starkhouse B (2005) Salmon Bay Natural Area pre-restoration monitoring 2004. Seattle Public Utilities, City of Seattle, WA

Toft JD, Cordell JR, Simenstad CA, Stamatiou LA (2007) Fish distribution, abundance, and behavior along city shoreline types in Puget Sound. N Am J Fish Manag 27: 465-480

Toft JD, Heerhartz SM, Cordell JR, Armbrust E, Ogston AS, Flemer EE (2009) Olympic Sculpture Park: Year 2 fish, epibenthos, and physical monitoring including additional beaches. Tech Rep SAFS UW 0902. School of Aquatic and Fishery Sciences, University of Washington. Seattle Public Utilities, City of Seattle, WA

Toft JD, Ogston AS, Heerhartz SM, Cordell JR, Flemer EE (2013) Ecological response and physical stability of habitat enhancements along an urban armored shoreline. Ecol Eng 57:97-108

Werner EE, Gilliam JF, Hall DJ, Mittelbach GG (1983) An experimental test of the effects of predation risk on habitat use in fish. Ecology 64:1540-1548

Zuur AF, Ieno EN, Walker N, Saveliev AA, Smith GM (2009) Mixed effects models and extensions in ecology with R. Springer, London

Submitted: May 18, 2015; Accepted: August 3, 2016

Proofs received from author(s): August 31, 2016 